\title{
Immunologic Identification of a Pulmonary Surfactant-Associated Protein of Molecular Weight $=6000$ Daltons
}

\author{
JEFFREY A. WHITSETT, WILLIAM M. HULL, BRYAN OHNING, GARY ROSS, AND \\ TIMOTHY E. WEAVER \\ University of Cincinnati College of Medicine, Department of Pediatrics, Division of Neonatology, \\ Cincinnati, Ohio 45267
}

\begin{abstract}
Hydrophobic, small molecular weight, surfactant-associated protein of $\mathrm{Mr}=6000$ (SAP-6) was isolated from bovine, canine, and human alveolar lavage and identified by silver staining after sodium dodecyl sulfate polyacrylamide gel electrophoresis gels. Lesser amounts of protein of $\mathrm{Mr}=14,000,20,000$, and 26,000 daltons also copurified with SAP-6, likely representing oligomers of the $\mathrm{Mr}=6,000$ dalton protein. In the absence of sulfhydryl-reducing agents, increased amounts of the larger forms of the protein were observed. Antisera generated against bovine SAP-6 were used to further characterize the protein and distinguish it from the more abundant surfactant-associated glycoprotein of $\mathrm{Mr}=35,000$ (SAP35) present in mammalian surfactants. Rabbit antisera generated against the bovine hydrophobic protein recognized SAP-6 and lesser amounts of the proteins of $\mathrm{Mr}=$ $14,000,20,000$, and 26,000 daltons. The SAP-6 antisera were reactive against the hydrophobic proteins from human, bovine, and canine surfactants as assessed by immunoblot analysis after sodium dodecyl sulfate polyacrylamide gel electrophoresis. SAP-6 antisera did not detect bovine SAP-35 the abundant surfactant-associated glycoprotein, by immunoblot analysis; however, some reactivity of the anti-SAP-6 was detected against purified bovine SAP-35 by a sensitive enzyme-linked immune-adsorbant assay. Anti-SAP-6-did not react with bovine serum components either by immunoblot or by enzyme-linked immune-adsorbant assay. Monospecific antisera generated against bovine SAP-35 did not detect SAP-6 by immunoblot analysis. Immunoblot analysis of the protein in exogenous replacement surfactant preparations, Surfactant-TA and calf lung surfactant extract, utilizing anti-SAP-6 and anti-SAP-35 demonstrated that both preparations were enriched in SAP-6 and lacking in SAP-35. Surfactantassociated proteins, present in bovine lung-based replacement surfactants, are immunologically identified as SAP6 and its oligomers. (Pediatr Res 20: 744-749, 1986)
\end{abstract}

\section{Abbreviations}

SDS-PAGE, sodium dodecyl sulfate polyacrylamide gel electrophoresis

ELISA, enzyme-linked immune-adsorbant assay Mr, molecular weight

Received December 24, 1985; accepted March 24, 1986

Correspondence Jeffrey A. Whitsett, M.D., University of Cincinnati College of Medicine, Department of Pediatrics, Division of Neonatology, 231 Bethesda Avenue, Cincinnati, OH 45267-0541.

This work was supported in part by Research Career Development Award HL 01024 from the National Institues of Health, HL 28623, HD 11725 (J.A.W.); HD 07200 (J.A.W., T.E.W.); HL 36055 (T.E.W.); HL 07527 (G.R.) and support from the Children's Hospital Research Foundation, Cincinnati, OH.
SAP-6, surfactant-associated protein(s) Mr = 6000; 14,000

SAP-35, surfactant-associated protein $\mathrm{Mr}=35,000$ (apoprotein A, glycoprotein A, PSAP)

CLSE, calf lung surfactant extract

HPLC, high-performance liquid chromatography

Mammalian pulmonary surfactant is composed primarily of phospholipids and associated proteins. Two major protein groups have been previously identified: a surfactant-associated glycoprotein of 30-40,000 daltons first described by King and Clements (1), herein called SAP-35 and smaller molecular weight proteins detected in a variety of mammalian surfactants $(1-12)$. Clarification of the identity and nature of the various surfactantassociated proteins has been incomplete. The structure and biosynthesis of SAP-35 have recently been more fully elucidated (13-18). This glycoprotein is synthesized from an $\mathrm{Mr}=26,000$ dalton polypeptide precursor which is posttranslationally modified by proteolytic cleavage of a leader sequence and the addition of complex carbohydrate with resultant size and charge heterogeneity, $\mathrm{Mr}=32,000-36,000$ daltons, pI 4.6-5.2 (13-19). Sulfhydryl-dependent oligomerization accounts for the larger forms of SAP-35 detected in mammalian surfactants (20). Proteolytic fragments of SAP-35 have been identified in protein preparations isolated from lavage of patients with alveolar proteinosis and from other mammalian surfactants migrating as proteins of small molecular weight (15). While the glycoprotein SAP-35 binds phospholipids and may confer the structural organization of tubular myelin to surfactant lipids, it remains unclear whether SAP-35 is required for the biophysical activity of surfactants (11). Recent work from our laboratory has demonstrated virtually full biophysical activity of surfactant preparations containing only smaller molecular weight protein and lacking SAP-35 (12). The identity of several extremely hydrophobic, small molecular weight proteins was most clearly described by Phizackerly et al. (10) studying porcine surfactant. Two distinct small molecular weight proteins were recently isolated from rat surfactant (17). Small, hydrophobic protein has also been isolated from lung surfactant extracts of porcine, bovine, and rat origin (4-7) and more recently from canine, bovine, and human surfactants (12). The origin of these various small molecular weight proteins is unclear but some have been suggested to arise from proteolytic cleavage of SAP-35 (11). The present work was performed to clarify the nature of these proteins. Small molecular weight, hydrophobic surfactant-associated protein(s) were identified in surfactant and their lack of relationship to SAP-35 was clarified. Various molecular weight forms of hydrophobic surfactant protein was found to result from aggregation of some surfactant- 
associated protein(s) which were distinguished from the major surfactant associated glycoprotein (SAP-35) or its fragments.

\section{METHODS}

Isolation of surfactant. Lipid-associated proteins were isolated from lung lavage material obtained from adult dogs and cows after sacrifice as previously reported $(12,15,25)$. Proteins were also isolated from human surfactant obtained from human cadavers at autopsy or from lung lavage of consenting adults. Protocols involving human materials were approved by the Committee on Human Research, University of Cincinnati College of Medicine. In animal studies, the trachea was cannulated and the lung lavaged three times with several lung volumes of iced $0.9 \%$ $\mathrm{NaCl}, 50 \mathrm{mM} \mathrm{Na}_{2} \mathrm{HPO}_{4}$, and $5 \mathrm{mM}$ EDTA, $\mathrm{pH}$ 7.2. Cells and debris were removed by centrifugation at $800 \times g$ for $10 \mathrm{~min}$ (twice) and a particulate fraction was collected by centrifugation at $40,000 \times g$ for $30 \mathrm{~min}$ at $4^{\circ} \mathrm{C}$. The pelleted material was then resuspended in the above buffer containing $1 \mathrm{mM}$ phenylmethylsulfonylfluoride and sonicated for $10 \mathrm{~s}$ with a Branson sonifier. Surfactant was pelleted by repeated centrifugation at $40,000 \times g$ for $30 \mathrm{~min}$ at $4^{\circ} \mathrm{C}$.

Purification of hydrophobic proteins from surfactant and surfactant replacement extracts. The surfactant pellet was further processed by extraction in ether/ethanol $(3: 1)$ at $-30^{\circ} \mathrm{C}$ for 16 $\mathrm{h}(12,15)$. Ether/ethanol extracts containing SAP-6 were evaporated to near dryness and redissolved in chloroform. Purification of SAP-6 then proceeded essentially as described by Phizackerley et al. (10). The dried residue was dissolved in chloroform and applied to a BioSil-HA column $(2.5 \times 40 \mathrm{~cm}$, Bio-Rad, Richmond, CA) equilibrated in chloroform. Lipidprotein fractions were recovered by stepwise elution with chloroform-methanol mixtures $(200 \mathrm{ml}$ each) with successive increase in concentration of methanol (10\% intervals) in chloroform. The SAP-6 protein was eluted at approximately 3:2 chloroform:methanol. Aliquots from each column fraction were assayed for protein by SDS-PAGE. Fractions containing SAP-6 were also quantitated by a fluorescamine assay using bovine serum albumin in the presence of $1 \%$ SDS as standard (23).

Surfactant-TA (22) and CLSE were dissolved in chloroform and the protein purified essentially as described for the SAP-6 above. Surfactant-TA (Tokyo Tanabe Co., Tokyo, Japan) was provided through the cooperation of Ross Division of Abbott Laboratories, North Chicago, IL. Proteins were further delipidated prior to immunoblot analysis using Sep-packs from Waters, Inc., Bedford, MA and by HPLC, using preparative silicic acid chromatography and elution with a linear gradient of methanol in chloroform (12). Protein was added to the Sep-pack column in chloroform. Phospholipid was eluted with chloroform; the protein eluted with $100 \%$ methanol for analysis.

Gel analysis of SAP. Proteins were analyzed after separation using SDS-polyacrylamide gels made $3-27 \%$ polyacrylamide. Samples were lyophilized and resuspended in sample buffer as described by Laemmli (24) in the presence of $\beta$-mercaptoethanol. Gels were stained using a minor modification of the procedures as Sammons et al. (25) in which $5 \%$ acetic acid was used to control background staining following a 5- to 10 -minute $\mathrm{Na}_{2} \mathrm{CO}_{3}$ color development step. Low molecular weight protein markers were obtained from BRL Incorporated, Bethesda, MD: trypsin inhibitor $(6,200)$, lysozyme $(14,000) \beta$-lactalbumin $(18,400), \alpha$ chymotrypsin $(25,700)$, and ovalbumin $(43,000)$. Radiolabeled protein markers were obtained from Amersham Inc., Arlington, IL.

Immunoblot and ELISA analysis of SAP. Antisera were prepared against bovine SAP-6 by repeated injection of the bovine protein into albino rabbits. The antigen contained protein of $\mathrm{Mr}$ $=6,000$ and smaller amounts of $\mathrm{Mr}=14,000$ dalton protein as assessed by silver staining analysis after one-dimensional SDSPAGE. Monospecific antisera were also prepared in rabbits against purified bovine SAP-35 by repeated injections of the purified protein in Freund's complete adjuvant. Bovine SAP-35 was purified to homogeneity as previously reported (26). The antisera recognized only SAP-35 by immunoblot analysis of whole bovine surfactant after one- and two-dimensional gel electrophoresis. Neither resultant antisera were reactive against bovine serum, bovine serum albumin, or fetal calf serum. For immunoblot analysis, whole bovine surfactant, purified bovine SAP-35, or SAP-6 were separated by SDS gel electrophoresis as previously described $(13,15)$. Proteins were transferred electrophoretically to nitrocellulose and incubated with the antisera followed by horseradish peroxidase-conjugated goat antirabbit $\mathrm{IgG}$, and developed as described by Towbin et al. (27), except that 4-chloro-napthol was used as the substrate. Single phase ELISA assays, by plating either purified bovine SAP-6, bovine SAP-35, whole surfactant were utilized to characterize the antisera or bovine serum. Dose responses of the antigens and antisera were performed to optimize conditions dilutions for the ELISAs. Horseradish-peroxidase coupled goat antirabbit antiserum was used to develop the color reaction as previously reported (20).

\section{RESULTS}

Silicic acid column purification of the hydrophobic proteins from ether/ethanol extracts of bovine surfactant resulted in the identification of a predominant protein migrating $\mathrm{Mr}=6,000$ (Fig. 1A). After SDS-PAGE in the presence of the sulfhydryl

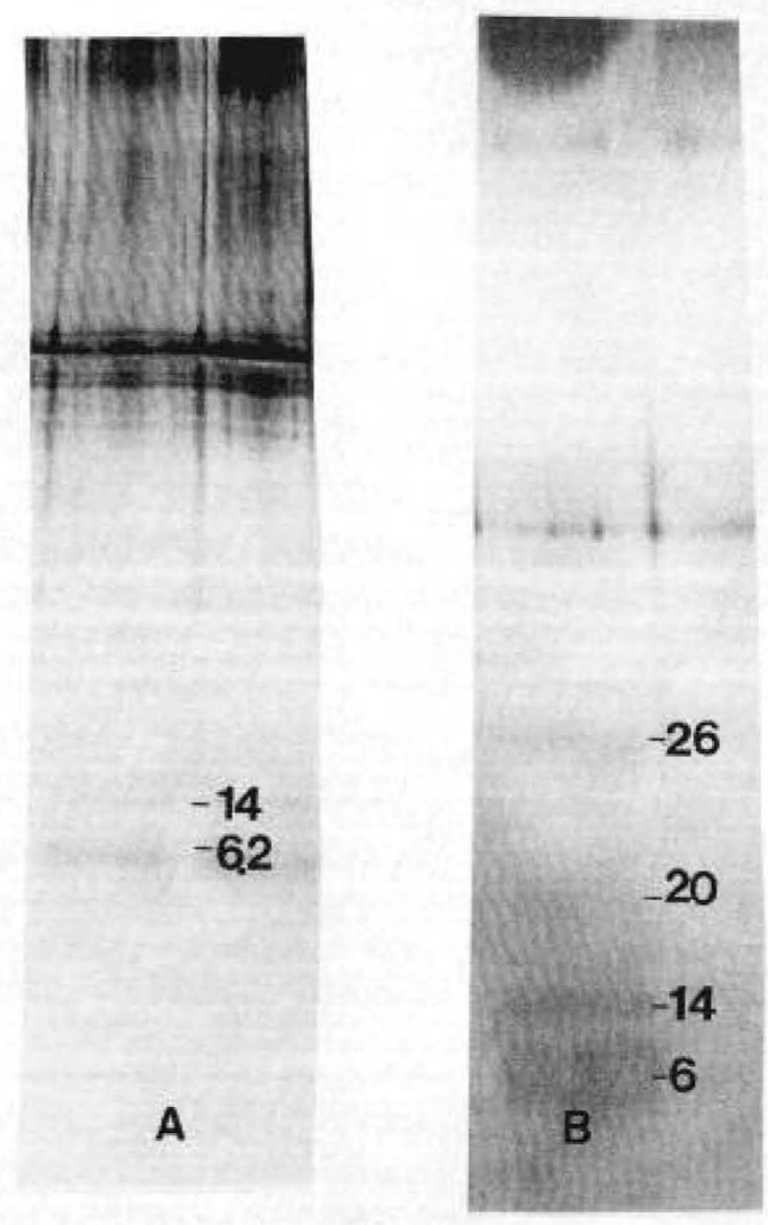

Fig. 1. Silver stain analysis of hydrophobic proteins from bovine surfactant. $A$ represents approximately $2 \mu \mathrm{g}$ of the bovine protein, separated by a gradient of $3-27 \%$ polyacrylamide in presence of $\beta$ mercaptoethanol, as assessed by silver staining. Proteins of $\mathrm{Mr}=6,000$ and 14,000 daltons are identified. $B$ represents approximately $4 \mu \mathrm{g}$ of the proteins separated in the absence of reducing agent. Proteins of $\mathrm{Mr}$ approximately $6,000,14,000,20,000$, and 26,000 (arrows) were observed in absence of $\beta$-mercaptoethanol. Bands of higher molecular weight are artifacts routinely observed with this silver staining method, Mr approximately 65,000 daltons. 
reducing agent $\beta$-mercaptoethanol, the majority of the protein migrated with $\mathrm{Mr}=6,000$ daltons (SAP-6). Progressively decreasing amounts of protein were also observed with approximate molecular weight of multimers of SAP- $6(14,000,20,000$, and 26,000 daltons) (Fig. $1 A$ ). In the absence of $\beta$-mercaptoethanol, increased amounts of protein migrating at $\mathrm{Mr}=20,000$ and 26,000 were evident (Fig. $1 B$ ) Proteins migrating with $\mathrm{Mr}=$ $6,000,14,000$, and 20,000 daltons were also present in the absence of reducing agent. Reduction and alkylation (12) resulted in identical migration patterns of the proteins observed after treatment with $\beta$-mercaptoethanol, the predominant band migrating with $\mathrm{Mr}=6,000$ (not shown).

Antisera generated against SAP-6 were highly reactive against purified bovine SAP- 6 and whole bovine surfactant but did not react with bovine serum and fetal calf serum by immunoblot or ELISA assay (Fig. 2). Immunoblot analysis of the whole bovine surfactant using the antisera against SAP-6 resulted in the identification of a predominant immunoreactive protein of $\mathrm{Mr}=$ 6,000 and lesser amounts of proteins detected at $\mathrm{Mr}=14,000$, 20,000 , and 26,000 (Figs. 3 and 4). The immunoreactive proteins comigrated with the SAP- 6 proteins identified by silver staining (Fig. 1). The major surfactant-associated protein, SAP-35, was not reactive by immunoblot analysis with this SAP-6 antisera (Fig. 3); however, some cross-reactivity of the anti-SAP-6 with purified bovine SAP-35 was detected in the ELISA assay (Fig. 2 ). In contrast, bovine SAP-35 and its unglycosylated form of $\mathrm{Mr}=26,000$ were readily detected by immunoblot analysis with monospecific antisera generated against SAP-35 [Fig. 3 (lanes $c$ and $d)$ ]. Monospecific antisera generated against bovine SAP-35 did not react with SAP-6 in immunoblot analyses of whole bovine surfactant or of purified SAP-6. Reactivity of antibovine SAP-35 with SAP-6 was also noted in the ELISA assay but was active with SAP-6 only at higher concentrations of antisera.

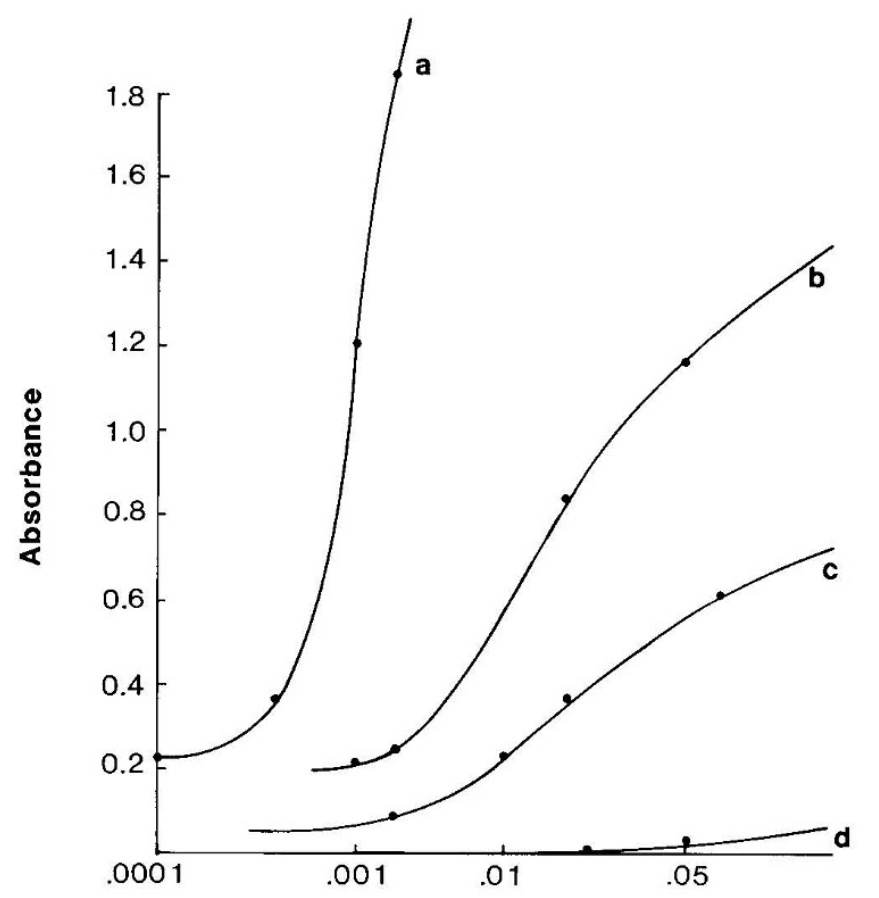

Microliters Antisera

Fig. 2. Reactivity of antisera generated against bovine SAP-6 in ELISA assay. Reactivity of rabbit anti-SAP-6 and anti-SAP-35 with purified SAP-6 and purified bovine SAP-35 were compared. Dilutions (semilog) of the antisera (x axis) were tested against optimal concentrations of plated antigen. A, rabbit anti-SAP-35 versus purified SAP-35; $B$, rabbit anti-SAP-6 versus purified SAP-6; $C$, rabbit anti-SAP-6 versus purified SAP-35; and $D$, rabbit anti-SAP-6 versus whole bovine serum.

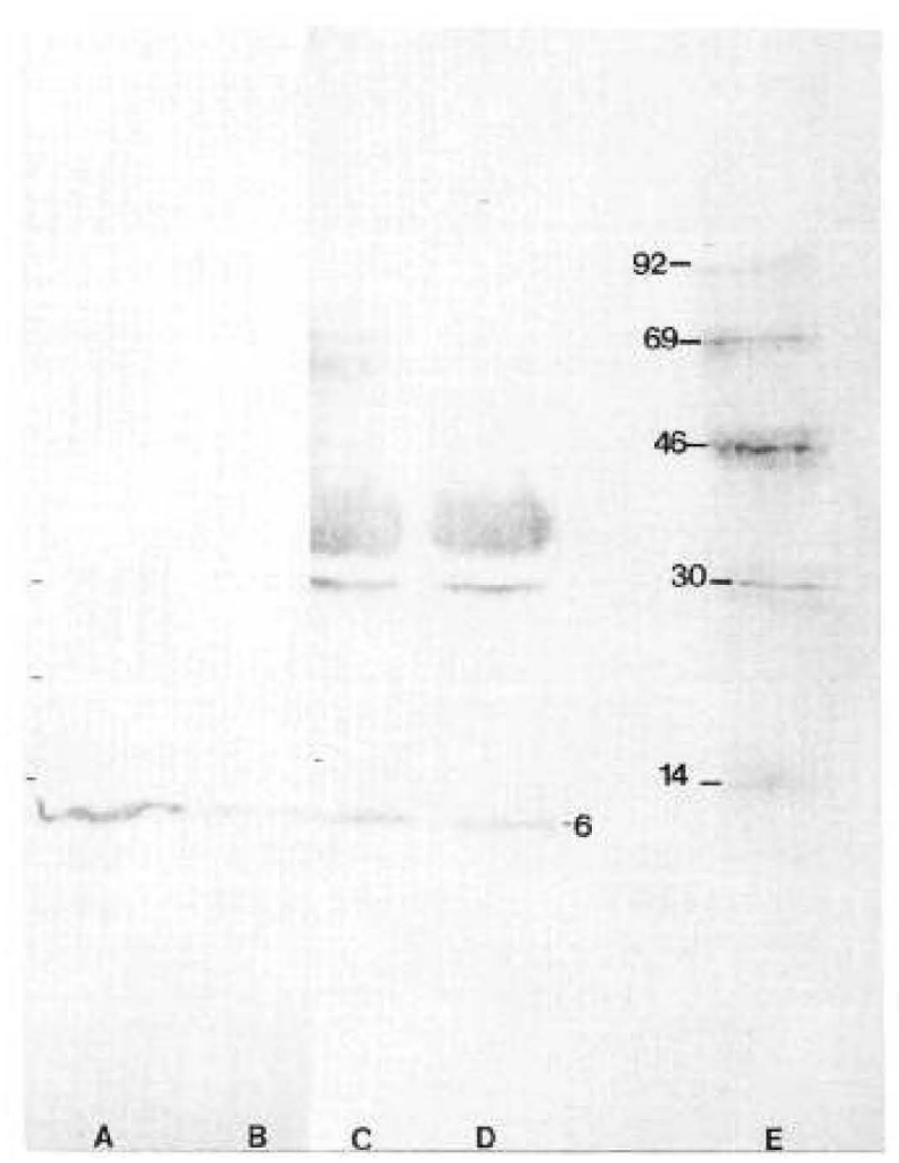

Fig. 3. Immunoblot analysis of whole bovine surfactant first using rabbit antisera versus bovine SAP- 6 and then antisera versus bovine SAP35. Whole bovine surfactant (approximately 50 and $25 \mu \mathrm{g}$ protein in adjacent wells) was separated by gradient SDS-PAGE in the presence of $\beta$-mercaptoethanol and immunoblotted with rabbit anti SAP-6 (lanes $A$, $50 \mu \mathrm{g} ; B, 25 \mu \mathrm{g} ; C, 50 \mu \mathrm{g} ; D, 25 \mu \mathrm{g}$ of whole bovine surfactant). A major portion at $\mathrm{Mr}=6,000$ is observed in all lanes with lesser amounts at $14,000,20,000$, and 26,000 daltons. After treatment with anti-SAP- 6 half of the immunoblot $(C, 50 \mu \mathrm{g}, D, 25 \mu \mathrm{g})$ was then reacted with rabbit antibovine SAP-35, identifying protein of $\mathrm{Mr}=26,000$ and 35,000. SAP35 was not detected with anti-SAP-6 $(A, B)$ but was readily detected with monospecific antisera versus SAP-35 $(C, D)$. Protein $\mathrm{Mr}=26,000$, identified with the anti-SAP-35, was consistent with detection of the unglycosylated form of bovine SAP-35. Lane $E$ represents autoradiograms of labeled protein markers cotransferred to nitrocellulose $\times 10^{-3}$ daltons.

Species differences. SAP-6 was isolated from human, canine, and bovine pulmonary surfactant and their migration was similar as compared by SDS-PAGE and silver staining (not shown). Immunoblot analysis of these purified proteins with rabbit antibovine SAP-6 antisera demonstrated reactivity with each of the small molecular weight proteins from the various species tested (Fig. 5). Weaker cross-reactivity was observed against rat and rabbit SAP-6 (not shown). These findings contrast sharply with the species specificity of the antisera generated against bovine SAP-35 (Fig. 5). Variable amounts of the $\mathrm{Mr}=14,000$ dalton and larger forms were noted in some preparations although the relative amounts usually followed the order $\mathrm{Mr}=6,000>14,000$ $>20,000>26,000$ daltons in all species tested.

Immunoblot analysis of protein purified from surfactant-TA. Antisera generated against bovine SAP-6 were used to test for reactivity with hydrophobic proteins purified from the surfactant replacement extracts used clinically for treatment of hyaline membrane disease: Surfactant-TA and CLSE. Identical reactivity was observed in both preparations, staining was observed primarily at $\mathrm{Mr}=6,000$ daltons (Fig. 6). Both replacement surfac- 


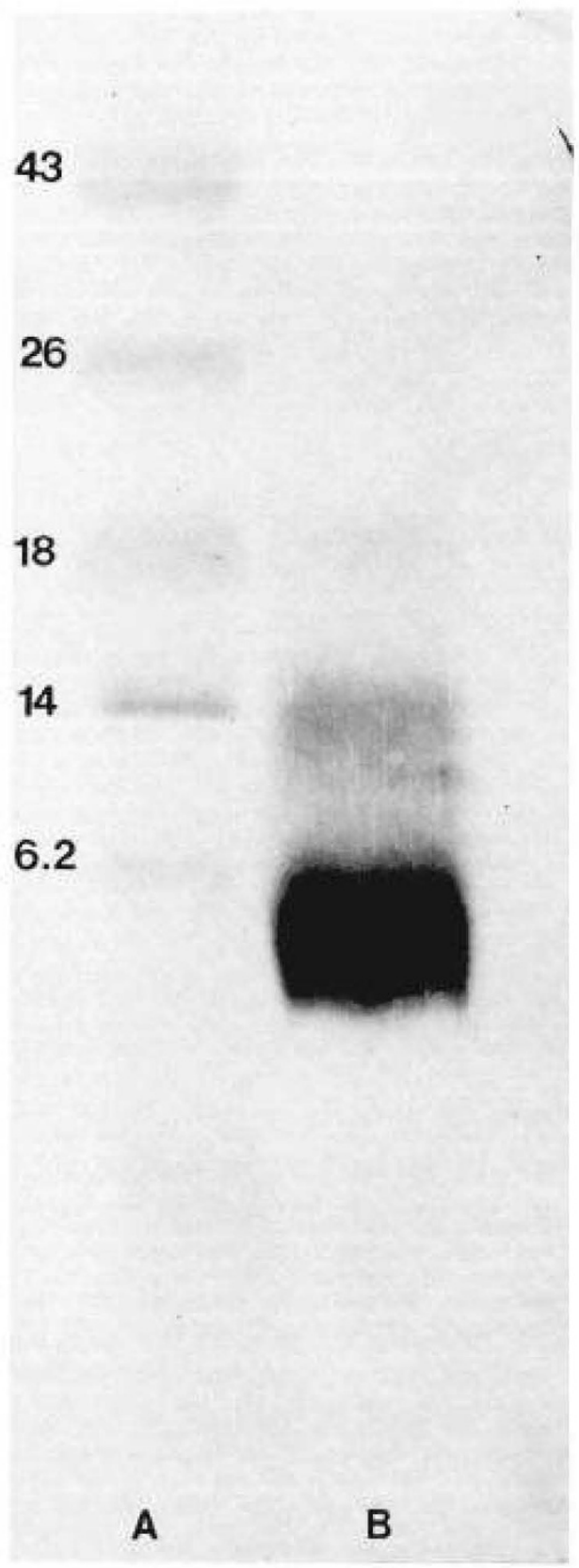

Fig. 4. Immunoblot of purified SAP-6. Antisera versus SAP-6 was reacted with purified bovine SAP-6 $(10 \mu \mathrm{g})$ in order to demonstrate the smaller amounts of the multimeric forms (lane $B$ ). Proteins $\mathrm{Mr}=6,000$, $14,000,20,000$, and 26,000 were detected by immunoblot with antiSAP- 6 after SDS-PAGE in the presence of $\beta$-mercaptoethanol; these observations are consistent with presence of nonsulfhydryl-dependent oligomers or aggregation of the protein. Low molecular weight markers are visualized in lane $A$.

tants were reactive in ELISA and immunoblot assays using antiSAP-6. No immunoreactivity was detected by immunoblot analysis of both replacement surfactant preparations using antisera against bovine SAP-35 (not shown).

\section{DISCUSSION}

In the present work, we have described small, hydrophobic, SAPs isolated from bovine, canine, and human surfactants. These protein(s) migrated with apparent molecular weight, $\mathrm{Mr}$ $=6,000$ daltons with progressively lesser amounts of protein migrating at $\mathrm{Mr}=14,000,20,000$, and 26,000. These proteins were distinguished from the major surfactant-associated glycoprotein, SAP-35 by immunoblot experiments with antisera generated against bovine SAP-6 and SAP-35. Immunoreactive forms of SAP-6 were demonstrated for the canine, human, and bovine proteins using antibovine SAP-6 antisera. These observations support a unique identity of hydrophobic protein(s) (SAP-6) and suggest that some of the larger hydrophobic proteins of $\mathrm{Mr}$ $=14,000,20,000$, and 26,000 daltons present in ethanol:ether extracts of surfactant may be 6000 dalton oligomers or aggregates of peptide. These forms of SAP- 6 were a major protein component identified in the bovine replacement surfactants, surfactantTA and CLSE, as assessed by silver staining (12) and presently by immunoblot analysis and ELISA assay. Since extensive purification from phospholipids is required to visualize SAP-6, these studies do not preclude the presence of other smaller hydrophobic proteins in surfactant or the surfactant extracts.

Confusion regarding the identity of SAPs has resulted both from varied terminology and methods used to identify the proteins. Smaller molecular weight proteins previously isolated and partially characterized from lipid-rich extracts of lung lavage by several groups of workers include extremely hydrophobic proteins which appear to be distinct from SAP-35 (4-6, 10, 12). Other studies have suggested that the smaller proteins (termed apoprotein B) were derived from proteolysis of the more abundant surfactant protein SAP-35 (11). Consistent with the latter hypothesis, small molecular weight proteins isolated from canine and human surfactant migrating at $\mathrm{Mr}=14-16,000$ were identified as acidic fragments of SAP-35 by comparison of peptide maps (15) (Ross G, Whitsett J, unpublished observations). Smaller molecular weight proteolytic fragments of SAP-35 were immunoreactive by immunoblot using antisera generated against human SAP-35 and do not represent SAP-6 (15). It is possible that these small molecular weight peptides derived from SAP-35 were previously detected by others in preparations of alveolar lavage material.

Antisera generated against SAP-6 further support the distinction of the hydrophobic proteins from SAP-35. These antisera were unreactive against serum components and were reactive against SAP-6 from canine, bovine, or human sources. In immunoblot experiments, antibovine SAP-35 (a monospecific antisera generated in our laboratory) was not reactive against species homologous protein of $\mathrm{Mr}=6,000,14,000,20,000$, or 26,000 daltons, further distinguishing these proteins from SAP-35. Antisera against bovine SAP-35, although highly reactive against bovine SAP-35 were unreactive against the human and canine SAP- 35 by immunoblot analysis. Thus, the immunoreactivity of SAP-6 appears to be conserved in these species, while that of SAP-35 is highly species specific. However, some cross-reactivity of anti-SAP-6 with purified SAP-35 at low serum dilutions was consistently observed by a sensitive ELISA assay (using preparations lacking detectable SAP-6). Similarly, anti-SAP-35 was active with SAP- 6 by ELISA although only at low titers. Whether this relates to shared antigenic epitopes between the two proteins has not been clarified.

A further line of evidence supporting the distinct origins of SAP- 6 and SAP-35 comes from a comparison of amino acid compositions. The amino acid sequence derived from the human SAP-35 gene recently reported (18), and recent work from this laboratory describing the amino acid composition of SAP-35 and SAP-6, support the distinct identity of SAP-6 and are not consistent with its production by proteolysis of SAP-35 $(12,15$, 18). Comparison of the amino acid composition of any region of the published sequence of SAP-35 demonstrates that a composition similar to SAP-6 cannot be generated from a linear sequence of SAP-35 $(12,18)$. Similar, but not identical, amino acid compositions have been reported from porcine, bovine, and canine hydrophobic small molecular weight proteins $(4,5,10$, 12).

Higher molecular weight forms. The relative migration of the larger hydrophobic proteins of $\mathrm{Mr}=14,000,20,000$, and 26,000 


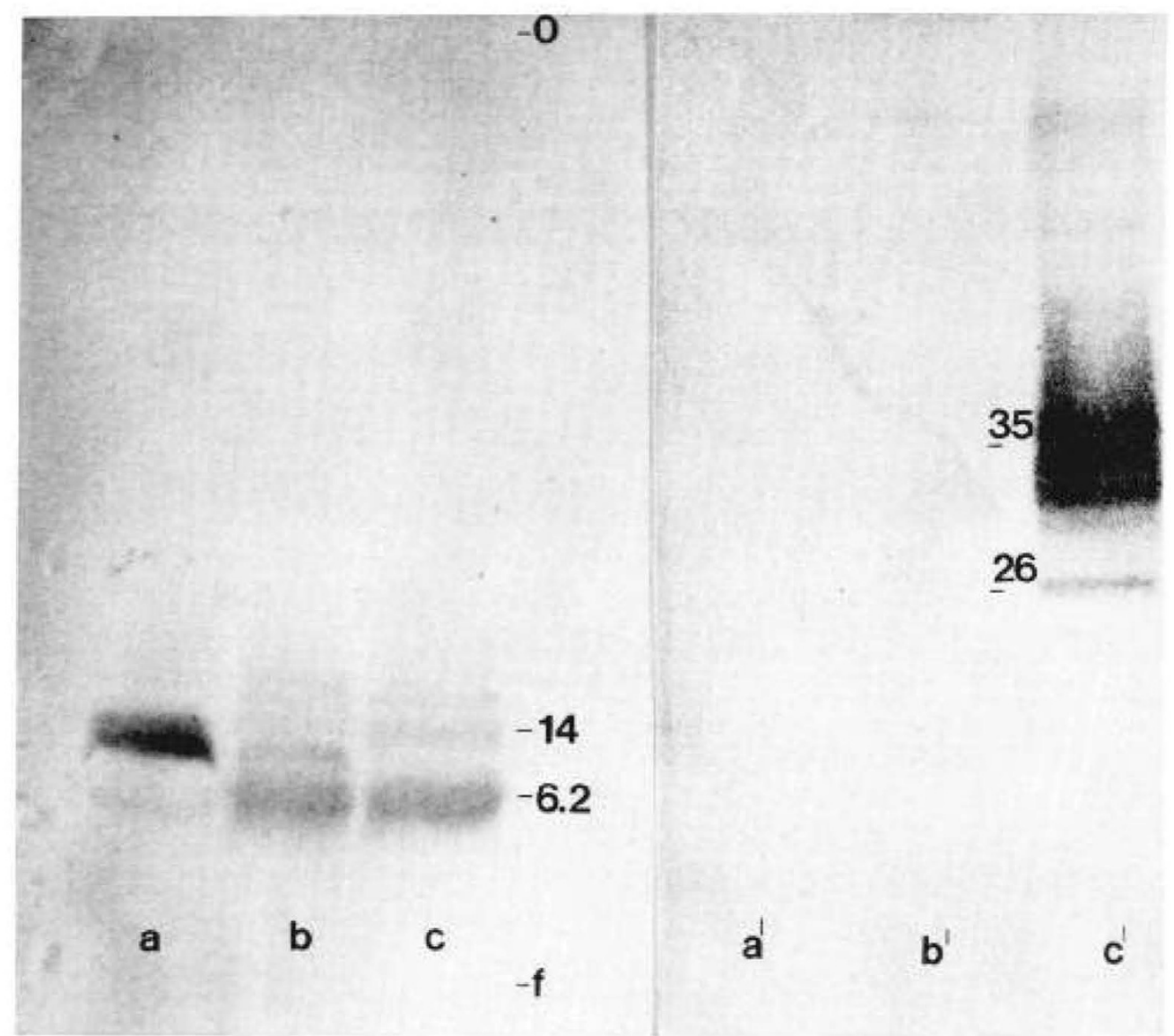

Fig. 5. Immunologic reactivity of SAP-6 from human, canine, and bovine surfactant. SAP-6 was purified from human $(a)$, canine $(b)$, and bovine $(c)$ surfactants and separated by $3-27 \%$ SDS-PAGE in presence of $\beta$-mercaptoethanol. Approximately $2 \mu \mathrm{g}$ was placed in each lane and immunoblotted with anti-SAP-6. Immunoblot of whole human $\left(a^{1}\right)$ canine $\left(b^{1}\right)$, bovine $\left(c^{1}\right)$ surfactant (approximately $40 \mu \mathrm{g}$ ) using antibovine SAP35 antisera. SAP-6 was not reactive using antisera generated against bovine SAP-35 $(5 b)$. Antisera directed against bovine SAP-35 were nonreactive against SAP-35 from canine or human surfactant $\left(a^{1}, b^{1}\right)$ but readily identified bovine SAP-35 $\left(c^{1}\right)$.

in SDS-PAGE is consistent with the larger forms representing possible multimers of 6,000 dalton protein. It remains possible that more than one small molecular weight protein accounts for the observed heterogeneity. Present evidence does not support a direct structural relationship between SAP-6 and SAP-35; it remains unclear whether SAP- 6 might be generated by proteolysis of other lung proteins.

The increase in larger molecular weight forms of SAP-6 detected in the absence of reducing agents support the possibility that both sulfhydryl bonding as previously suggested (4) and nonsulfhydryl aggregation and/or interpeptide bonding of 6,000 dalton protein might account for the larger forms. Possible anomalous migration of proteins in the absence of sulfhydryl reduction in SDS-PAGE, and the presence of lipid, may complicate size estimations in the previous and present studies. Molecular weight determinations are only estimates based on relative migration. The copurification, immunoreactivity, and previously reported resistance of the SAP- 6 to various proteolytic enzymes and endoglycosidases further supports a close structural relationship among the peptides of $\mathrm{Mr}=6,000,14,000,20,000$, and 26,000 (12). The precise identification of SAP-6 and possibly other small molecular weight proteins suggested by the work of Phizackerly et al. (10) and Wang et al. (17) will require complete amino acid sequence analysis.

The hydrophobic proteins may be of clinical importance, specifically, we have demonstrated that SAP-6 is associated with biophysical activity of replacement surfactant extracts (12). We have demonstrated, by silver staining analysis after SDS-PAGE
(12) and now by immunologic reactivity with SAP-6 antisera, that SAP-6 and lesser amounts of protein of $\mathrm{Mr}=14,000$ daltons are significant protein components of the two clinically tested surfactant replacement preparations of bovine origin: CLSE and surfactant-TA (28-34). Bovine SAP-35 was not detected by silver stain or by immunoblot analysis of CLSE or surfactant-TA with antisera generated against bovine SAP-35. Although a role of SAP-35 in the biophysical activity of surfactant has been suggested, interpretation of experiments supporting its biophysical activity may have been complicated by the presence of hydrophobic proteins, specifically SAP-6, in the surfactant lipid extracts tested $(20,35)$. The biophysical activity of CLSE and surfactant-TA include nearly instantaneous surface adsorption and dynamic surface properties comparable to natural surfactant suggest that the smaller molecular weight protein(s) and specifically SAP-6 are associated with biophysical activity of surfactant $(4,22,28,29)$.

The present study characterizes SAP of 6000 daltons on the basis of its migration in SDS-PAGE and immunoreacivity with a specific antiserum. Coupled with available amino acid composition data (12), these results suggest an origin for SAP-6 distinct from SAP-35. The site of synthesis, extent of processing, integration into the surfactant complex, secretion into the airway, and the functional domain(s) of SAP-6 remain to be elucidated.

Note added in proof. Two distinct N-terminal amino acids are detected in SAP-6 preparations. Size heterogeneity of SAP-6 protein observed in absence of reduction may be related to the presence of more than one hydrophobic 6,000 dalton peptide. 


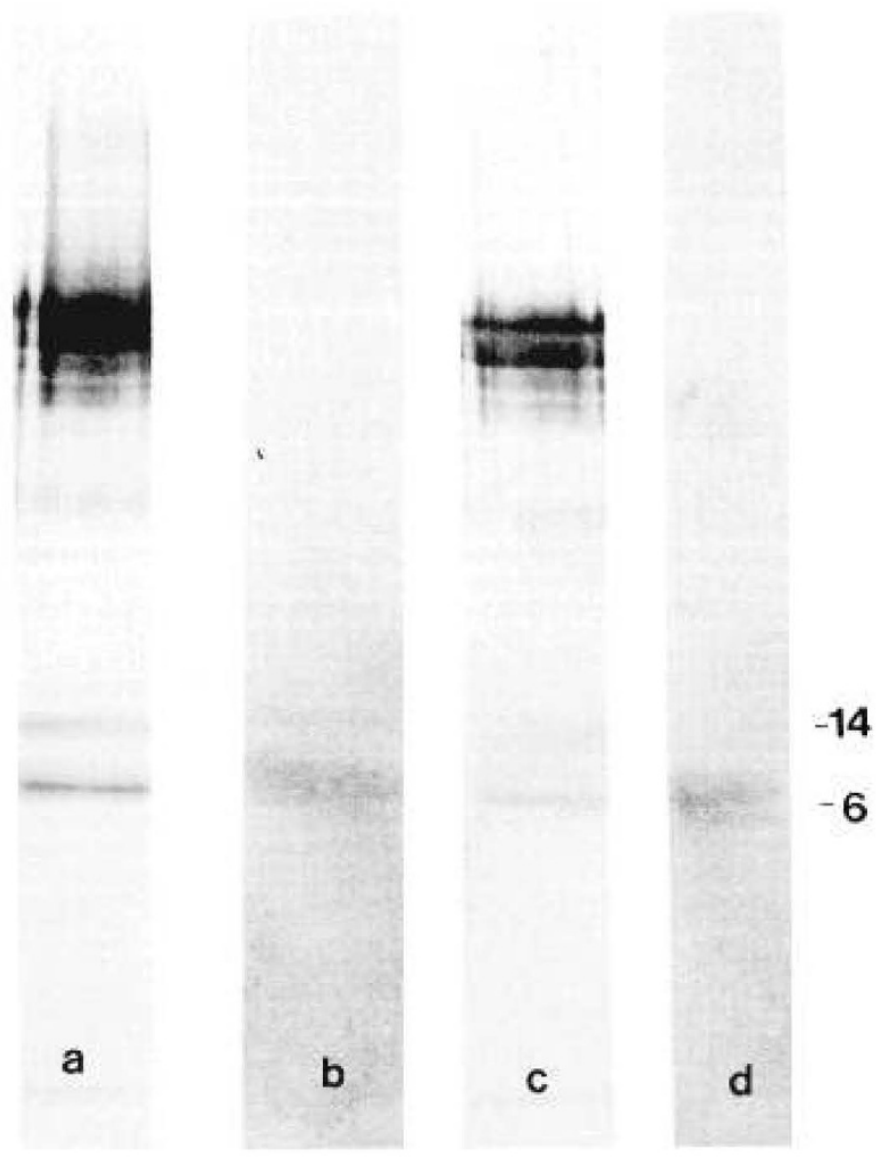

Fig. 6. Silver stain and immunoblot of SAP-6 from bovine surfactant and surfactant-TA. Approximately $2 \mu \mathrm{g}$ of purified protein isolated from bovine surfactant $(a, b)$ or surfactant-TA $(c, d)$ was separated by SDSPAGE on duplicate gels which were subsequently analyzed by immunoblotting analysis and silver staining. Protein was transferred to nitrocellulose and reacted with antibovine SAP- 6 antisera and the immunoblots developed as described in "Methods" $(b, d)$. Identical samples were subjected to silver staining ( $a$, bovine surfactant; $c$, surfactant-TA). Proteins of $\mathrm{Mr}=6,000$ and 14,000 daltons were the major proteins detected by both methods. Silver stain artifacts are observed at $\mathrm{Mr}=$ 65,000 in lanes $a$ and $c$. Identical proteins, $\mathrm{Mr}=6,000$ and 14,000 were detected in CLSE (data not shown).

Acknowledgment. CLSE was the kind gift of Robert H. Notter, Rochester, NY.

\section{REFERENCES}

1. King RJ, Clements JA 1972 Surface active materials from dog lung. II Composition and physiological correlations. Am J Physiol 223:715-726

2. King RJ 1982 Pulmonary surfactant. J Appl Physiol 53:1-8

3. King RJ, Klass DJ, Gikas EG, Clements JA 1973 Isolation of apoproteins from canine surface active material. Am J Physiol 224:788-795

4. Tanaka Y, Takei $\Upsilon$, Kanazawa Y 1983 Lung surfactants. II. Effects of fatty acids triacylglycerols and protein on the activity of lung surfactant. Chem Pharm Bull 31:4100-4109

5. Suzuki Y 1982 Effect of protein, cholesterol and phosphatidylglycerol on the surface activity of the lipid-protein complex reconstituted from pig pulmonary surfactant. J Lipid Res 23:62-69

6. Claypool WD, Wang DL, Chander A, Fisher AB 1984 An ethanol/ether soluble apoprotein from rat lung surfactants augments liposome uptake by isolated granular pneumocytes. J Clin Invest 74:677-684

7. Wright JR, Benson BJ, Williams MC, Goerke J, Clements JA 1984 Protein composition of rabbit alveolar surfactant subfractions. Biochim Biophys Acta 791:320-332

8. Katyal SL, Singh G 1984 Analysis of pulmonary surfactant apoproteins by isoelectric focusing. Biochim Biophys Acta 794:411-418

9. Suzuki Y, Nakai E, Ohkawa K 1982 Experimental studies on the pulmonary surfactant reconstitution of surface-active material. J Lipid Res 23:53-61

10. Phizackerly PJR, Town M-H, Newman GE 1979 Hydrophobic proteins of lamellated osmiophilic bodies isolated from pig lung. Biochem $\mathrm{J}$ 183:731736

11. King RJ, Martin H, Mitts D, Holmstrom FM 1977 Metabolism of the apoproteins in pulmonary surfactant. J Appl Physiol 42:483-491

12. Whitsett JA, Notter RH, Ohning BL, Ross G, Meuth J, Holm BA, Shapiro DL, Weaver TE 1986 Hydrophobic 6,000 kilodalton protein and its importance for biophysical activity in lung surfactant extracts. Pediatr Res 20:460-467

13. Whitsett JA, Weaver T, Hull W, Ross G, Dion C 1985 Synthesis of surfactantassociated glycoprotein A by rat type II epithelial cells. Primary translation products and post-translational modification. Biochim Biophys Acta 828:162-171

14. Floros J, Phelps DS, Taeusch HW 1985 Biosynthesis and in vitro translation of the major surfactant-associated protein from human lung. J Biol Chem 260:495-500

15. Whitsett JA, Hull WM, Ross G, Weaver TE 1985 Characteristics of human surfactant-associated glycoprotein(s) A. Pediatr Res 19:501-508

16. Whitsett JA, Ross G, Weaver T, Rice W, Dion C, Hull W 1985 Glycosylation and secretion of surfactant-associated glycoprotein A. J Biol Chem 260:15273-15279

17. Wang DL, Chander A, Fisher AB 1985 Amino acid composition of low molecular weight hydrohobic surfactant apoproteins. Fed Proc 44:1024(abstr)

18. White RT, Damm D, Miller J, Spratt K, Schilling J, Hawgood S, Benson B, Cordell B 1985 Isolation and characterization of the human pulmonary surfactant apoprotein gene. Nature 317:361-363

19. Weaver TE, Whitsett JA, Hull WM, Ross G 1985 Identification of canine pulmonary surfactant-associated glycoprotein A precursors. J Appl Physiol 58:2091-2095

20. Weaver TE, Hull WM, Ross GF, Whitsett JA 1985 Intracellular and oligomeric forms of surfactant-associated apolipoprotein(s) A in the rat. Biochim Biophys Acta 827:260-267

21. Benson BJ, Williams MC, Sueishi K, Goerke J, Sargeant T 1984 Role of calcium ions in the structure and function of pulmonary surfactant. Biochim Biophys Acta 793:18-27

22. Fujiwara T 1984 Surfactant replacement in neonatal RDS. In: Robertson B, van Golde LMG, Batenburg JJ (eds) Pulmonary Surfactant. Elsevier, Amsterdam, pp 479-503

23. Bohlen P, Stein S, Dairman W, Udenfriend S 1973 Fluorometric assay of proteins in the nanogram range. Arch Biochem Biophys 155:213-220

24. Laemmli UK 1970 Cleavage of structural proteins during the assembly of head bacteriophage $\mathrm{T}_{4}$. Nature 227:680-685

25. Sammons DW, Adams LD, Nishizawa EE 1981 Ultrasensitive silver-based color staining of polypeptides in polyacrylamide gels. Electrophoresis 2:135141

26. Ross GF, Meuth J, Ohning B, Kim X, Whitsett JA 1985 Purification of canine surfactant-associated glycoproteins $A$ : identification of a collagenase resistant domain. Biochim Biophys Acta (in press)

27. Towbin H, Staehelin T, Gordon J 1979 Electrophoretic transfer of proteins from polyacrylamide gels to nitrocellulose sheets: procedure and some applications. Proc Natl Acad Sci USA 76:4350-4354

28. Notter RH, Finkelstein JN, Taubold RD 1983 Comparitive adsorption of natural lung surfactant, extracted phospholipids and artificial phospholipid mixtures to the air-water interface. Chem Phys Lipids 33:67-80

29. Notter RH 1984 Surface chemistry of pulmonary surfactant: interactions of individual components. In: Robertson B, van Golde LMG, Batenburg JJ (eds) Pulmonary Surfactant. Elsevier, Amsterdam, The Netherlands, pp 17:65

30. Fujiwara T, Chida S, Watabe Y, Maeta H, Morita T, Abe T 1980 Artificial surfactant therapy in hyaline membrane disease. Lancet 1:55-59

31. Smyth JA, Metcalf IL, Duffty P, Possmayer F, Bryan MH, Enhorning G 1983 Hyaline membrane disease treated with bovine surfactant. Pediatrics 71:913 917

32. Kwong MS, Egan EA, Notter RH, Shapiro DL 1985 A double-blind clinical trial of calf lung surfactant extract for the prevention of hyaline membrane disease in extremely premature infants. Pediatrics 76:585-592

33. Shapiro DL, Notter RH, Morin FC, Deluga KS, Golub LM, Sinkin RA, Weiss KI, Cox C 1985 A double-blind, randomized trial of a calf lung surfactant extract administered at birth to very premature infants for prevention of the respiratory distress syndrome. Pediatrics 76:593-599

34. Enhorning G, Shennan A, Possmayer F, Dunn M, Chen CP, Milligan J 1985 Prevention of neonatal respiratory distress syndrome by tracheal instillation of surfactant: a randomized clinical trial. Pediatrics 76:145-153

35. Benson BJ, Hawgood S, Williams MC 1984 Role of apoprotein and calcium ions in surfactant function. Exp Lung Res 6:223-236 